\title{
A critical account of the rise and spread of 'leadership': the case of UK healthcare
}

\author{
Graham P. Martin \& Mark Learmonth
}

\begin{abstract}
This paper considers the rise of 'leadership' in discourses relating to the British health service, and the application of the term to increasingly heterogeneous actors. Analysing interviews with NHS chief executives from the late 1990s, and key policy documents published since, the authors highlight how leadership has become a term of choice among policymakers, with positive cultural valences which previously predominant terms such as 'management' now lack. They note in particular how leadership is increasingly conferred not only on those in positions of formal power but on frontline clinicians, patients and even the public, and how not just the implementation but the design of policy is now constructed as being led by these groups. Such constructions of the distribution of power in the health service, however, contradict the picture drawn by academic work. The authors suggest, therefore, that part of the purpose of leadership discourse is to align the subjectivities of health-service stakeholders with policy intentions, making their implementation not just everyone's responsibility, but part of everyone's sense of self. Given the realities of organizational life for many of the subjects of leadership discourse, however, the extent to which leadership retains its current positive associations and ubiquity remains to be seen.
\end{abstract}

\section{Published in: $\quad$ Social Science \& Medicine 74(3): 281-288 \\ http://www.elsevier.com/locate/socscimed}

doi:10.1007/s10689-007-9130-3

\section{Introduction}

'Leadership' has been the focus of increasing attention for both policymakers and academics. Seen as a key component of organizational success, the popular, policy and academic literatures on leadership have grown greatly over the last three decades. In the private and public sectors, leadership has become more than merely a function within management: it is constructed as something to be enacted by employees across an organization, not just those at the apex (Bryman, 1999). In the public sector in particular, where power is more diffuse and organizational objectives more plural, there has been an increasing emphasis in recent years on the importance of spreading leadership qualities across organizations (Hartley \& Allison, 2000). Recent British governments have been particularly strong exponents of this 'call to leadership' (e.g. Cabinet Office, 1999), and the National Health Service (NHS) has been seen much policy rhetoric, and financial investment, around developing 'leadership capacity' (e.g. NHS Institute, 2005).

Much contemporary leadership research is concerned with themes such as how leadership can be understood and conceptualized, and how its benefits can best be harnessed by individuals and organizations. Thus leadership researchers often draw on debates in the wider social sciences to ask whether leadership is best enacted through, for example, 'transformational' (Bass, 1985), 'distributed' (Spillane, 2005; Gronn, 2002), or 'collective' (Denis et al., 2001) approaches. But 
while there are significant disagreements about its precise nature, it is largely accepted that leadership should be treated as a real, empirically distinctive entity. Furthermore, it seems moreor-less axiomatic within these debates that leadership (at least when properly practised) is beneficial for individuals and organizations.

The idea that leadership is universally beneficial seems holds for most studies of leadership in health. Reviewing this field, Gilmartin and D'Aunno (2007) draw attention to several distinctive aspects of healthcare delivery (e.g. the existence of "powerful professionals, especially physicians, who dominate many aspects of day-to-day work in healthcare," p.390)—distinctive features of healthcare which, they contend, add complexities to attempts to transfer leadership theories from elsewhere. Nevertheless, they offer conclusions that resonate with the assumptions of mainstream leadership research outlined above. In healthcare, Gilmartin and D'Aunno (2007, p.408) suggest, "leadership is positively and significantly associated with individual and group satisfaction, retention and performance". Such ideas are echoed in the ways in which healthcare professionals are asked or aspire to 'do' leadership. In the US, for example, the influential National Center for Healthcare Leadership (NCHL) declares that it

works to assure that high quality, relevant and accountable leadership is available to meet the challenges of delivering quality patient healthcare in the 21st century. NCHL's goal is to improve health system performance and the health status of the entire country through effective healthcare management leadership. ${ }^{1}$

In contrast to these dominant ideas, however, a small but increasingly influential body of work is emerging within organization studies, which we label 'critical leadership studies' (see, e.g., Alvesson \& Sveningsson, 2003; Barker, 2001; Ford 2006; Ford et al., 2008; Grint, 2010). Such work, though adopting diverse theoretical orientations, is united by scepticism towards leadership's supposed benefits. Indeed, leadership, as the "process whereby one or more individuals succeeds in attempting to frame and define the reality of others" (Smircich \& Morgan, 1982, p.257), is generally seen as a nefarious political project, one concerned with facilitating subtle forms of control: leaders seducing their followers into accepting what may not be in their interests. One response of some critical leadership scholars in resisting its seductive appeal is to focus less on what leadership is and more on what it does.

Here, in this vein, we critically consider the rise of 'leadership' in NHS discourse, over the last 10-15 years in particular, drawing on ideas from the critical leadership literature. We ask: what are the consequences-for individual healthcare staff, and for healthcare policy and practice as a whole_-of labelling things 'leadership'? In doing so, we draw on empirical fieldwork conducted with NHS managers in the 1990s, and then key policy documents produced from the late 1990s to the present. We highlight a shift in the terminology used to refer to 'administration', then 'management', then 'leadership' in the NHS. We note an expansion in the ways in which the term 'leadership' is applied in the policy literature, as an attribute not just of formal leaders/managers, but to an increasingly plural set of stakeholders, including clinicians and even patients and the public. We illustrate how this policy focus on leadership might be understood as seeking to affect the work and even the subjectivities of health-service professionals and other actors (such as patients and the public). By 'subjectivities', we mean individuals' senses of themselves, their biographies and their personal trajectories. These we understand, following Knights and Willmott (1989, p.537), as neither essential and innate to the individual, nor externally imposed by social structure, but rather produced through "involvement in relations of power through which conceptions of identity are generated." As such, subjectivity is not "that creative autonomy or personal space not yet captured by political economy" (p.549), but is rather "intimately bound to power/knowledge relations which traverse both the subjects and (what are conventionally seen as) social structures" (Newton, 1998, p.418). Our concern here, then, is with

\footnotetext{
${ }^{1}$ http://www.nchl.org/static.asp?path=2887, accessed 23 August 2010.
} 
what leadership does—or might do—-to the subjectivities of NHS staff.

In particular, we highlight how health-service staff are increasingly represented not just as the objects of policy interventions, but as subjects implicated in policy design. We suggest that claims made by health policy about the engagement of professionals as leaders in the design and delivery of reform are best understood as efforts to reconstitute these actors' subjectivities: a co-optive means of 'governing at a distance' that complements more coercive modes of rule such as performance management and associated surveillance regimes.

\section{Methods}

Our paper draws, in sequence, on two sources. First, we offer an analysis of empirical material: interviews with 16 NHS hospital chief executives, conducted by ML in 1998-1999. Each interview lasted 45-60 minutes and was audio-taped and transcribed. Participants had agreed to be interviewed in the context of research investigating how NHS chief executives make sense of their professional world. Interviews were framed by an opening question- "What do you see as the heart of your job?" - and proceeded to roam across a wide set of topics in a fluid, informal manner. This process produced a dataset of about 110,000 words. Our analytical focus on 'administration', 'management' and 'leadership' was prompted by a striking feature of many interviews. As a preliminary to the interviews, primarily to contextualize their answers, each respondent was invited to describe her/his professional background. An exchange such as this was typical:

I came into the health service as, at that stage, a career administrator, straight from university; onto the administrators' training scheme and moved into management, as management developed in the NHS.

Their initial emphasis on administration having been succeeded by management led to a search for other references to 'administration', 'management' and 'leadership' within the transcripts (for full methodological details, see Learmonth, 2005). Thus we consider how participants constructed their roles in terms of administration, management and leadership. Our analysis is framed by an understanding of language, and of particular signifiers, as (at least partially) performative: where performative language, following Royle (2000, p.9) is language that "does something, in actuality, in reality, with reality." This analysis highlights in particular how participants spoke about 'management' and 'leadership' in largely coterminous ways-leadership and management are more-or-less synonymous, in a way which seems curiously outdated only just over a decade later.

These findings prompted us to investigate the development of leadership discourse in official policy in the intervening period. Our second set of sources is therefore major NHS policy documents produced by the Department of Health $(\mathrm{DoH})$ from around the time of the interview data through to the present day. We considered all DoH command papers published since 1997 (including white papers_-statements of policy—and green papers-more formative consultation/discussion documents) relating to the NHS as a whole, and excluded those which related to social care, particular clinical areas, and particular professions. Together, these command papers represent the most important statements of NHS direction over the period in question. This period saw a number of wider changes in NHS policy that might influence the construction of leadership: an initial focus on top-down reform in the period 1997-2000 was displaced by a return to market mechanisms in from 2001 onward (Klein, 2006). From 2008, the emphasis shifted further, towards quality as an organising and defining principle in the NHS, to be achieved through professionally led change. We chose our cut-off date of 1997 for three reasons, pragmatic and substantive: first, it coincided roughly with the date of the interviews, and so documents published at this time would have informed the views of the chief executives 

Limited

\begin{tabular}{|c|c|c|}
\hline Year & Title & Publication details \\
\hline 1997 & The New NHS: Modern, Dependable. & London: The Stationery Office \\
\hline 1998 & Our Healthier Nation: a Contract for Health. & 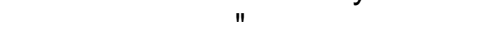 \\
\hline 1999 & Saving Lives: Our Healthier Nation. & " \\
\hline 2000 & $\begin{array}{l}\text { The NHS Plan: A Plan for Investment, a Plan for } \\
\text { Reform. }\end{array}$ & " \\
\hline 2002 & $\begin{array}{l}\text { Delivering the NHS Plan: Next Steps on Investment, } \\
\text { Next Steps on Reform. }\end{array}$ & " \\
\hline 2003 & $\begin{array}{l}\text { Building on the Best: Choice, Responsiveness and } \\
\text { Equity in the NHS. }\end{array}$ & " \\
\hline $2004 a$ & $\begin{array}{l}\text { The NHS Improvement Plan: Putting People at the } \\
\text { Heart of Public Services. }\end{array}$ & " \\
\hline $2004 b$ & Choosing Health: Making Healthy Choices Easier. & " \\
\hline 2006 & $\begin{array}{l}\text { Our Health, Our Care, Our Say: A New Direction for } \\
\text { Community Services. }\end{array}$ & " \\
\hline 2008 & $\begin{array}{l}\text { High Quality Care for All: NHS Next Stage Review } \\
\text { Final Report. }\end{array}$ & $"$ \\
\hline
\end{tabular}

Table 1: Policy literature analysed

interviewed in the late 1990s; second, a new Labour government was elected in 1997 which promised to modernize public services including the NHS, and which saw 'better leadership' as a key means of achieving this (Parker, 2004); third, from around this time web-based HTML and/or PDF versions of all white and green papers became available, assisting our sampling and analysis. In addition to command papers, we also included High Quality Care for All, the final report of the NHS Next Stage Review, which is not a white or green paper, but which forms a central part of current NHS policy and future plans, especially in relation to improving quality through professionally led change.

For each of the policy documents included in this set of sources (Secretary of State for Health [hereafter SoSH] 1997, 1998, 1999, 2000, 2002, 2003, 2004a\&b, 2006, 2008) (see Table 1), we undertook an analysis process which consisted of a careful reading and rereading of the documents as a whole, followed by keyword searches for three key terms: admin*, manag* and lead*. We then read the text around these terms with three key questions in mind: what is meant by this term; what it asks NHS stakeholders (managers, clinicians, patients) to do; and what role it ascribes to these stakeholders. Our analysis was framed by these questions with a view to uncovering the discursive function of leadership and associated terms, and also paid attention to the chronology of the documents, seeking to highlight shifts in terminology and evolutions in the way these terms have been deployed.

This approach was taken with a view to ensuring systematicity and transparency in our treatment of the documents and analysis of data, but as with any such discursively oriented approach, it is one which also rests on interpretation, and thus on our subject positions as authors. Two consequences of this in particular should be broached. Firstly, our interpretations are not intended to be received as categorical or definitive, and we acknowledge that the texts we present can be understood in various ways. We offer our interpretations in the belief that the social world is inherently ambiguous; although we seek to justify our assertions by reference to the texts themselves and the (textual and social) contexts in which these are located, the social world can ultimately only be apprehended subjectively. Secondly, in this paper we juxtapose two rather different sources of data: the self-described actions of hospital chief executives of 12 years ago, and the carefully crafted policy rhetoric of the last 10 years. The former represent individuals' (post hoc accounts of their) views, beliefs and actions. The latter constitute powerful documents which seek to influence views, beliefs and actions: we cannot infer from them that these documents have been successful in this attempt to influence. However, we do argue that the powerful potential of the discourses contained in these documents is illustrated by the talk of chief executives and by other empirical studies, and we suggest some of the consequences this 
policy discourse on leadership might have if this potential is realized.

In the next section, we consider the discourses of administration, leadership and management in the talk of the chief executives, noting how they and others use these words to create, legitimize and delegitimize different roles for themselves and others. In particular, we highlight the potential and limits of the discursive potential of 'management', suggesting reasons why it may have been displaced by 'leadership' in the intervening period. We then turn to the policy literature from 1997 to the present, and the developing notion of leadership advanced in these documents not just for managers, but for other healthcare actors as well. In the discussion and conclusion sections, we consider the interests promoted by these ideas of leadership in NHS policy, and what this might mean for the future of the discourse.

\section{Administration, leadership, management}

There have been striking changes in the way that organizational roles in the NHS have been represented over the last thirty years or so. From the origins of the NHS until the mid-1980s, 'administration' was the term overwhelmingly preferred for formal organizational functions, within official documents and mundane discourse (Gorsky, 2008). Administration was finally displaced from its dominance by 'management' in the mid-1980s, following the publication of the NHS Management Inquiry, the Griffiths Report (Klein, 2006), and for the next 10-15 years those with formal organizational authority (including clinicians) were almost invariably referred to as managers (Hunter, 1996). Today, administration (insofar as it features at all in contemporary accounts) is presented as low-status and peripheral (Parker \& Dent, 1996).

The significance of such discursive changes was particularly evident when reviewing the interviews with NHS trust chief executives conducted in the late 1990s. Reread today, the way that management and leadership were deployed in these interviews seems strikingly different from contemporary practice. Administration was denigrated as it is today; however, in the late 1990s, management (rather than leadership) was the standard term for any kind of organizing activity. Although 'leadership' was used by participants, no strong distinctions between management and leadership were drawn.

However, as far as administration was concerned, although most chief executives interviewed had been administrators, being an administrator was (emphatically) not a desirable role anymore. For example, when talking of the trust's top management team in place immediately before her appointment, one respondent described how they had been unable to cope with the new demands of partnership working:

There [had been] no radical or strategic thinking enough to do that sort of work; [trust] used to be peopled by a bunch of administrators, basically.

Here, the use of administration was performative in the sense that it amounted to more than setting out a state of affairs. It was clearly derogatory. But the denigration of administrators also allowed the speaker to do something else with her words - to construct a sense of her own role. She was (emphatically) not an administrator, she was radical and strategic.

By the late 1990s, words associated with management and leadership seemed to have constructed and legitimated an organizational world in which chief executives felt they had supremacy; 'administrator', on the other hand, did things that undermined the prestige and authority they sought. What contrasts strikingly with today's discourses, however, is how management tended to be the term of preference-in places where leadership would likely be used today. This phenomenon is especially apparent in respondents' talk of management in the context of clinical work. For example:

I felt that $[\ldots]$ the emergence of clinical governance was an opportunity to refocus the doctors' role on clinical management, leadership and the management increasingly of clinical practice informed by evidence, rather than on the management of service delivery and staffing budgets and so on.

Here, the speaker deploys the term management to represent functions he considers to be 
legitimate medical duties: "clinical management, leadership and the management increasingly of clinical practice informed by evidence." Leadership is mentioned, but it is not privileged, and seems to be a casual synonym for management rather than a distinctive entity in its own right. In performative terms, one way to interpret what was being attempted by such talk at this time is to understand it as an effort to re-present conventional medical work as managerial work: the hope being, perhaps, that if managerial language became taken-for-granted in doctors' routine talk and thinking, those doctors might come to understand their own roles as managerial, at least in part. Indeed, another chief executive described her frustration at many doctors' refusal to recognize the managerial nature of their roles:

All consultants are managers — not all consultants would recognize that or recognize the implications of that as readily as others do, but they all manage resources, they all manage their time, manage junior medical staff.

If medical work should come to be seen as managerial in nature, it would perhaps imply that doctors should be accountable to the top manager - the chief executive-and furthermore that more traditional considerations for the NHS-especially ones based on welfarism and compassion — could be played down and rendered subservient to the tough job of ensuring good management (Parker, 2000).

\section{The limits to management discourse and managerialism}

As Grey (1999, p.572) has argued, "the insinuation of management into a huge range of human activities and actors previously thought of as lying outside the specialist domain of management [...] constitutes one of the key 'achievements' of managerialism." However, for chief executives, we see above how the term manager evidently remained vulnerable to being reconstructed by others as 'mere' administration. As a performative project, then, the 'managerialization' of language remained incomplete. In the wider policy context of NHS modernization from 1997, furthermore, a reliance on the word 'management' in government documents and ministerial speeches might signal an uncomfortably close continuity with the legacy of the new Right. Both these associations might discomfort many healthcare professionals, who might thus be expected to resist 'management' becoming the unnoticed, commonsense term for significant aspects of their work (Hewison, 1997). Thus the negative associations accumulated by management and administration may have assisted the popular and officially sanctioned turn to leadership that has, as we shall see, increasingly occurred. As Parker (2004, p.175) puts it, "management itself [... is] beginning to go out of fashion (now being discursively articulated as something rather like administration) and leadership [... is] the new panacea."

For those in charge of the NHS today, then, part of the attractiveness of the discourse of leadership may be that it does not (at least yet) have the negative connotations that management has gained. 'Management' can be (re)constructed as being something like administrationconcerned with money, day-to-day bureaucratic functions etc.-whereas leadership can be constructed in attractively heroic terms. An early populariser of this idea in health was Rosemary Stewart, who sets up a hierarchy of terms with administration at its base and leadership at the apex:

Good managers are not necessarily good administrators, and a leader has a more important role to play away from the desk.

1. Administrators confirm in writing.

2. Managers direct.

3. Leaders point the way: they identify and symbolise what is important. (Stewart, 1989, p.5)

\section{The pluralization of leadership}

In the previous section, we focused on the discourses of administration, management and leadership in the self-descriptions of NHS chief executives in the late 1990s. We highlighted both the potentials of this discourse-in promoting particular constructions of the place of 
management in the NHS - and its limitations - as a discourse that also prompts resistance. However, we are not (merely) arguing for an understanding of leadership as a form of semantic inflation, aggrandizing and legitimizing the role of the administrator/manager. Rather, we suggest, there has been a discursive break between management and leadership (Parker, 2004), in which leadership is no longer merely a particular style or skill of good management, but an increasingly separate ontological category - a category that appeals to many who would not have traditionally been regarded as managers. In illustrating this, we now turn to our analysis of highprofile NHS policy documents since 1997, and the developing place, meaning and function of 'leadership' within these texts.

This notion of leadership as a quality to be distributed and dispersed among staff throughout the hierarchy, "from apex to frontline" (Hartley \& Allison, 2000, p.39), has informed health policy under Labour governments since 1997, with their ambition to transform publicservice provision through 'modernization' (Martin et al., 2009). The NHS Plan (SoSH, 2000) included an entire section on leadership, calling for "first class leaders at all levels of the NHS" (p.86). Its main focus, though, was on increasing the number of formal leadership positions outside NHS management and the medical profession, with the introduction of modern matrons, nurse consultants and new senior roles in the allied health professions. Additionally, the Plan announced policies designed to increase 'leadership capacity' among senior NHS managers:

NHS organizations should be led by the brightest and the best of public sector management. Leadership development in the NHS has always been ad hoc and incoherent with too few clinicians in leadership roles and too little opportunity for board members to develop leadership skills. That will now change. (p.87)

Other key policy documents from the late 1990s and the early 2000s emphasised the importance of high-level leadership in transforming NHS provision. An entire chapter of The New NHS (SoSH, 1997, chapter 4) was devoted to the role of Health Authorities "leading and shaping" the new NHS, "freed from unnecessary administrative activities so that they are properly able to lead the local NHS and ensure it delivers." Similarly, it is national government and regional Health Authorities which were identified as the main sources of leadership in the public health green and white papers of the late 1990s (SoSH, 1998, 1999).

Later policy documents, however, pluralized the notion of leadership. In line with wider reforms of the NHS which increasingly sought to "give frontline staff greater control over how local health services are delivered" in place of "the traditional top-down management approach" (SoSH, 2002, p.34), leadership was no longer solely the province of managers and Health Authorities, but something to be distributed wider. The NHS Improvement Plan (SoSH, 2004a) heralded more flexible roles for healthcare staff, including, for example, giving nurses "a lead role in improving the experience of patients in both the hospital and the community." (p.60). The Improvement Plan also announced the "new lead roles for commissioners" in the newly reinstituted NHS internal market, while the health and social care white paper, Our Health, Our Care, Our Say (SoSH, 2006) included various measures to promote "local leadership of wellbeing" (p.24).

Furthermore, this devolution of leadership from the centre towards frontline practitioners related not just to responsibility for instigating change, but for designing policy, too. Back in 2000, preparation of The NHS Plan had included "specialist teams involving front-line staff, professional groups, patient representatives-alongside senior doctors, nurses and managers" (SoSH, 2000, p.14). By the time of the Next Stage Review (SoSH, 2008), though, this earlier approach to consulting staff in policy development could be dismissed as marginalization, as staff themselves led the new vision:

In previous reviews of the NHS, frontline staff have been on the fringes or bystanders. This Review has been different. We and our colleagues in the NHS have been at its core. There has been an unprecedented opportunity for health and social care professionals to review the best available evidence, to discuss priorities with patients and the public, and develop compelling shared visions for our local NHS. 
The Review thus described itself as "the product of the work more [sic] than 2,000 clinicians and other staff in health and social care, who have shown tremendous leadership in creating, shaping and forming the conclusions" (p.17).

Frontline staff are not the only ones to be engaged in leading the policy agenda. In the process of local leadership described as giving rise to the Next Stage Review, patients too were claimed to have been central. In coming to its conclusions, the 2000 clinicians mentioned above "worked in partnership with thousands of patients, listened to the needs and aspirations of the public and set out comprehensive and coherent visions for the future" (p.17), to arrive at "local visions [that] made the case for national action to enable local change" (p.21). On an unprecedented scale (again, if policy discourse is to be believed), patients and the public are, like frontline staff, moving from the periphery into a central, leading role in health-policy development. Our Health, Our Care, Our Say (SoSH, 2006) purported to include the most wideranging public consultation ever, placing the public "more in control of the policy setting process itself first at national and then local level" (p.14). Two extensive phases of consultation ahead of publication of the white paper, which turned out to be "wholly consistent" (p.15) with one another, offered clear messages about how statutory provision on which they could rely needed to be supplemented by more choices when provision failed. With professionals, patients and the public leading the policymaking agenda in this way, the role of policymakers themselves shifts to a more modest one, of converting these views into a clear plan: the white paper itself sought only to "translate what people have said into a new strategic vision," "supporting choice and giving people more say over decisions that affect their daily lives" (p.17).

In the delivery of care, too, leadership is increasingly to reside with patients and the public as well as frontline staff, with improvements in services and health outcomes resting on "local communities leading for health" (SoSH, 2004b, pp.76-101), and on the choices increasingly delegated to individual patients (SoSH, 2006). This includes "new forms of community leadership" that involve "a new approach to unlocking the energy that lies within communities themselves" (SoSH, 2004b, p.82). Given this need to rely not only on the leadership of clinicians but of patients too in improving the health service, "we must [...] continue to empower patients with greater choice, better information, and more control" (SoSH, 2008, p.38). Leadership, then, is vested in an increasingly heterogeneous group of actors in these policy documents, with frontline staff, patients and even the public themselves empowered to lead change through their localized knowledge, their skills, their decisions: their agency.

Leadership discourse, decentralization and central power

This discourse of leadership (and empowerment) aligns well with other changes in policy in the NHS: the adoption of 'decentralization' as a mantra for reform (Greener et al. 2009); the efforts to shift the balance of power from acute hospitals to primary care-based commissioners (DoH, 2001); the creation of foundation hospital trusts as a means of promoting community ownership of secondary-care provision, with representation of frontline staff and patients as members and governors (Walshe, 2003); and the increased involvement of patients and the public in commissioning decision-making through Local Involvement Networks (Martin, 2009). Yet the pluralization of leadership sits rather less comfortably with what many commentators agree has been an increasing centralization of power in the NHS since 1997 (Greener et al. 2009). Centrally driven performance management; regulatory, audit and inspection agencies ranging from NICE to the Care Quality Commission; 'comptrol' through a heavily regulated and directed market for healthcare provision: all these are seen by academic commentators as drawing power in to the centre, and reducing the 'decision space'—and, one would presume, the ability to lead—of other agents.

Policy discourse itself presents no inherent contradictions in these divergent pressures, constructing instead a situation in which central authority supports, rather than directs, the leaders on the front line. Take, for example, this excerpt from the 2003 white paper Building on the 
Best (the emphases are ours):

Real change will happen at the front line, with support from the centre, fuelled by encouragement and expectation from patients and drawing on the experience of partner organisations and other experts. Change will need:

- a clear shared vision and values, owned by national and local leaders;

- supported by continued investment and capacity growth;

- delivered by empowered staff, with support from peers and experts;

- backed up by high quality information systems;

- informed by a stronger patient voice; and

- underpinned by a coherent system of incentives, regulation and inspection.

(SoSH, 2003, p.55)

In the policy construction of leadership, visions and values are owned by leaders, informed by patients and delivered by staff. Incentives, regulation and inspection, and the information systems that enable these managerial technologies to function, merely underpin and back up these empowered agents. Yet empirical research in the new NHS consistently shows that this is not the experience of managers, clinicians and staff, who find that while accountability may have been moved towards local health organizations and individual clinicians, power remains with the centre-a system of 'national paternalism with local accountability', as Greener and Powell (2008) call it.

\section{Discussion: the discursive appeal of leadership}

The previous sections attempt to illustrate two related shifts in discourse around policy and management in the NHS. Firstly, there has been a notable shift in the terminology used to describe one area of activity in the running of the health service, from 'administration', through 'management', to 'leadership'. Secondly, this label of 'leadership' has been applied to the activities (actual or aspirational) of increasingly heterogeneous actors, including not just those in senior management positions, but also clinicians (including 'frontline clinicians') in a wide variety of professions, and patients and the public themselves. Leadership is no longer something to be exercised by those in formal positions of authority alone, a particular style or commendable characteristic of management: it is something to be brought out in actors across and beyond the health service, and which is fundamental to the success of ambitions to raise NHS quality.

What this means in practice, though, is not so clear. For a start, we should reiterate, our second dataset relates to policy, rather than evidencing changes in the practice of NHS staff. If, however, we posit that these policies are intended to achieve some substantive change in the way in which managers, clinicians and patients go about their business, this gives rise to the question of whether it is possible for leadership to be pluralized to such an extent. If everyone is, or should be, a leader, then who is following? As is to be expected from high-level policy documents of the kinds considered above, there is little detail here about the substance of leadership, how it is to be exercised in practice. However, as critical leadership studies have shown, 'leadership' is at best a very broad signifier, and when subjected to closer scrutiny, often seems to connote nothing at all that can be empirically delimited (Alvesson \& Sveningsson, 2003; Kelly, 2008). In this light, the function of 'leadership' is better understood less as a meaningful label for a discernible set of empirical practices, and more in terms of its discursive properties. As Ford (2006, p.83) argues, the discourse of leadership can serve to constitute individuals' subjectivities, offering a particular way of being a professional manager:

This interest in effective leadership [offers] one of the prevailing discourses through which managers' self-identity is constructed and maintained. These discourses of leadership in the public sector, depicted within the broader modernization discourse, provide managers with a means of self-monitoring, in which managers are 'cultivated' to become 'autonomous, self-regulating, productive individuals'. 
Though it must compete with other discourses around what it means to be a manager, Ford finds that leadership can provide a powerful "vocabulary and way of behaving that constrains, influences and manipulates managers into how their very identities are constructed" (p.83).

If, regardless of the possibility or otherwise of enacting leadership, one function of leadership discourse is then to attempt to engender these particular subjectivities among managers, how might it work upon the other groups of health-service actors of whom it is demanded, such as frontline professionals, patients and the public? Learmonth (2005, p.631) argues that

throughout the public sector, the official endorsement of leadership to represent organizational practices can be interpreted, in part, as a growing recognition that calling activities 'leadership' does more than calling them 'management' (and, it goes without saying, more than 'administration') in terms of encouraging individuals to identify with policy aims.

In these terms, talk of leadership distributed across the NHS workforce and beyond might represent a rhetorical device that seeks to engage these groups in the reforms required, according to policy, to achieve certain desirable ends: modernization, increased performance, quality. Leadership discourse seeks, then, to create new "grids for the perception and evaluation of things" (Foucault, 1991; quoted in Motion \& Leitch, 2009, pp.1056-1057).

In particular, one aim of this discourse seems to be to mitigate the tensions between the policy vision of a decentralized NHS in which frontline practitioners are empowered, and the empirical reality of a health service in which the performance-management regime of the centre is as powerful as ever (perhaps more so) (Greener et al., 2009). This contradiction, between claimed decentralization and actual retention of power by the centre, is not unique to governments since 1997: for Klein (2008), all health ministers since the inception of the NHS, save for Enoch Powell, have done the same. The purpose served by leadership, and associated discourses around empowerment of patients and frontline staff, is to attempt to align the subjectivities of these peripheral agents with policy intentions-since even if the NHS is still centrally controlled, it nevertheless relies on the acquiescence of those beyond the centre for the achievement of policy aims, especially in the increasingly complex organizational context of the present-day NHS. The centralization-decentralization paradox is not new, then, but in a late-modern society composed of fragmented, autonomous individuals and a panoply of quasi-autonomous organizations, the need to draw on seductive as well as dictatorial logics of rule is all the more important for achieving policy aims.

Through devices such as the call to leadership, then, policy and its implementation are made not just everyone's responsibility, but also everyone's common aim-even their sense of self. This process of co-optation is pursued with varying degrees of subtlety in government policy documents. At one extreme, the claim made in Our Health, Our Care, Our Say (SoSH, 2006), that the policy of increased competition introduced in this white paper was based on a comprehensive process of consultation with the public, seems highly questionable when set against other, credible sources of information about the public's views on choice and competition (e.g. Clarke et al., 2007). Clarke et al. (2007) find a public that conceptualizes choice in much less marketoriented terms, and one that is actually resistant to the consumerist notion of its relationship to public-service provision proffered by policy. Other aspects of this co-optation into leadership are more subtle. The Next Stage Review (SoSH, 2008, p.17), a product of the leadership of "more than 2,000 clinicians and other staff in health and social care," and authored by a clinician (albeit an elite surgeon, life peer and then under-secretary of state for health), is perhaps more astute in the way it attempts to pluralize leadership.

This is not to say that doctors, nurses, patients and others credulously take up these policy discourses, simply because of the involvement or endorsement of high-profile clinicians, and unquestioningly become the subjects desired. There has long been an evident scepticism among medical practitioners, for example, towards the claims of civil servants to involve any more than 
an 'in-group' of clinicians in policy development (e.g. Grimley Evans \& Tallis, 2001). However, this may not matter if policy discourse succeeds in instilling these values of leadership into a sufficient number of clinicians, managers and patients across the health service. Certainly, policy discourses can achieve such outcomes: our first dataset illustrated the power of discourse in the talk of NHS chief executives; others have noted the power of managerial discourses to permeate the subjectivities of, for example, NHS doctors (Halford \& Leonard, 1999; Harrison, 2010); leadership discourse is widespread in the UK and elsewhere, its influence and power evident, for example, in the language of the NCHL in the United States. Thus a critical mass of actors identifying with leadership, and with the aims of policy, may be enough to minimize dissent. This could give rise to a process of stratification, similar to that noted by Harrison (2002) in relation to scientific-bureaucratic medicine, whereby those clinicians comfortable with the implications of the discourse of leadership are elevated to privileged positions at the expense of the bulk of their peers. A similar process might be identified in the way in which NHS public-participation policy seeks to identify, recruit and co-opt a particular stratum of the public for involvement, chosen for "the combination of their ordinariness - their very laity — and their extraordinary enthusiasm and armoury of reflexive skills" (Martin, 2008, p.49). If a sufficient number of patients and members of the public come to constitute themselves in terms of a notion of 'community leadership' that aligns their agency with policy aims (and thus contributes to the realization of these aims), the discourse will have succeeded. As Harrison (2010) argues, we should not underestimate the capacity of policy to reframe the subjectivities of health professionals and others, and the potential advantages conferred by the role of 'leader', both material and symbolic, may make it a difficult discourse to resist, despite its definitional imprecision and managerialist function.

\section{Conclusion: limits to leadership discourse?}

We have argued that within the UK NHS in the last 10-15 years, leadership has become the taken-for-granted discourse through which many organizational roles are represented, at least at policy level, and potentially by role-holders themselves. Today, it is not just administrators/managers who are to think of themselves as leaders, 'leader' is be enacted by all healthcare professionals. Even patients and the public, recent policy claims, can be(come) leaders.

In drawing attention to these changes, we have sought to use ideas drawn from critical leadership studies to disrupt assumptions about the nature of leadership. The health-related social-science literature has devoted little attention, critical or otherwise, to the prominence of leadership in healthcare policy, practice and discourse. We argue that drawing on what critical leadership studies have to say on the matter can enrich our understanding of the contemporary landscape of healthcare provision (cf. Davies, 2003). In particular, we have argued that the naturalization of leadership discourse does things that have the potential to permeate the subjectivities of those involved, to the extent that it might even make those 'leaders' construct themselves as driving such change. In other words, while "I am a leader" may be an attractive self-narrative, it also represents a powerful way in which policy imperatives might 'govern the soul' (Rose, 1990). Thus, the recent popularization of leadership represents a particularly important change for clinicians. In marked contrast to their tradition of strong resistance to administrative or managerial responsibilities (Kitchener, 2000), 'leadership' may make it more attractive for doctors to take on particular roles in organizations, and make them more sympathetic to policy changes of the kind traditionally opposed by the medical profession.

But what of the future? Our reading of the history of changes in organizational discourses within the NHS suggests that the positive cultural valences currently ascribed to leadership may not be enduring. Ford et al. (2008) argue that earlier changes in organizational language-from administration to management-were symptomatic of the need of policymakers to rebrand what were basically similar activities. It is not implausible, therefore, that the current turn to leadership may have been motivated, at least in part, by a similar desire to make the old appear new. Thus one risk for the status of leadership is the very popularity it enjoys. A major part of its rhetorical 
appeal would seem to lie in the contrasts that appear to exist between leadership and management. These contrasts would become increasingly hard to maintain if leadership discourses approached ubiquity, and management went out of use.

Furthermore, as Robinson and Kerr (2009, p.878) argue, there is often "an 'unrealistic optimism' regarding the virtue of [...] the leader" among leadership's proponents. In contrast, they argue that leadership represents "symbolic violence [particularly where] there are no democratic controls or forms of participation" (p.899). This remark seems especially pertinent in the context of contemporary healthcare settings, where the contradictions and compromises inherent in providing efficient services have made exploitation, surveillance and unfair treatment some of the defining features of life for many staff, particularly those near the bottom of the hierarchy (Carter, 2000; Finn et al., 2010; Learmonth, 2009). Although we have argued that the discourse of leadership is powerful, we would not suggest that merely rebranding certain practices as leadership would, in itself, transform experiences of those jobs for the better (cf. Newton, 1998). Rather, should there be little substantive change in the day-to-day experiences of these staff, then simply re-labelling activities under the (ostensibly positive) banner of leadership might be interpreted as a fig leaf to hide the more oppressive aspects of life in healthcare provision. Ultimately, if the gap between everyday organizational realities and the pronouncements of policymakers does not narrow, then for all its current popularity, leadership itself may become a focus for dissent and resistance.

\section{Acknowledgements}

The authors would like to thank four anonymous reviewers for their constructive comments.

\section{References}

Alvesson, M., \& Sveningsson, S. (2003). The great disappearing act: difficulties in doing 'leadership'. Leadership Quarterly, 14(3), 359-381.

Barker, R.A. (2001). The nature of leadership. Human Relations, 54(4), 1419-1442.

Bass, B.M. (1985). Leadership and Performance beyond Expectations. New York: Free Press.

Bryman, A. (1999). Leadership in organizations. In S.R. Clegg, C. Hardy \& W.R. Nord (Eds.), Managing Organizations (pp.26-42). London: Sage.

Cabinet Office (1999). Modernising Government. London: HMSO.

Carter, J. (2000). New public management and equal opportunities in the NHS. Critical Social Policy, 20(1), 61-83.

Clarke, J., Newman, J., Smith, N., Vidler, E., \& Westmarland, L. (2007). Creating Citizen-Consumers. London: Sage.

Davies, C. (2003). Some of our concepts are missing: reflections on the absence of a sociology of organisations in Sociology of Health and Illness. Sociology of Health \& Illness, 25(SI), 172-190.

Denis, J.-L., Lamothe, L., \& Langley, A. (2001). The dynamics of collective leadership and strategic change in pluralistic organizations. Academy of Management Journal, 33(4), 809-837.

Department of Health (2001). Shifting the Balance of Power within the NHS. London: Department of Health.

Finn, R., Learmonth, M., \& Reedy, P. (2010). Some unintended effects of teamwork in healthcare. Social Science \& Medicine, 70(8), 1148-1154.

Ford, J. (2006). Discourses of leadership: gender, identity and contradiction in a UK public sector organization. Leadership, 2(1), 77-99.

Ford, J., Harding, N., \& Learmonth, M. (2008). Leadership as Identity. Basingstoke: Palgrave.

Gilmartin, M.J., \& D'Aunno, T.A. (2007). Leadership research in healthcare. Academy of Management Annals, 1, 387-438.

Gorsky, M. (2008). The British National Health Service 1948-2008: a review of the historiography. Social History of Medicine, 21(3), 437-460. 
Greener, I., Exworthy, M., Peckham, S. \& Powell, M. (2009). Has Labour decentralised the NHS? Terminological obfuscation and analytical confusion. Policy Studies, 30(4), 439-454.

Greener, I., \& Powell, M. (2008). The changing governance of the NHS: reform in a postKeynesian health service. Human Relations, 61(5), 617-636.

Grey, C. (1999). 'We are all managers now'; 'we always were': on the development and demise of management. Journal of Management Studies, 36(5), 561-585.

Grimley Evans, J., \& Tallis, R. (2001). A new beginning for care for elderly people? British Medical Journal, 322, 807-808.

Grint, K. (2010). The sacred in leadership: separation, sacrifice and silence. Organization Studies, 31(1), 89-107.

Gronn, P. (2000). Distributed properties: a new architecture for leadership. Educational Management \& Administration, 28(3), 317-338.

Halford, S., \& Leonard, P.(1999). New identities? Professionalism, managerialism and the construction of self. In M. Exworthy (Ed.), Professionals and the New Managerialism in the Public Sector (pp.83-101). Buckingham: Open University Press

Harrison, S. (2002). New Labour, modernisation and the medical labour process. Journal of Social Policy, 31(3), 465-485.

Harrison, S. (2010). Co-optation, commodification and the medical model: governing UK medicine since 1991. Public Administration, in press.

Hartley, J., \& Allison, M. (2000). The role of leadership in the modernization and improvement of public services. Public Money \& Management, 20(2), 35-40.

Hewison, A. (1997). The language of management: an enduring challenge. Journal of Nursing Management, 5(3), 133-144.

Hunter, D.J. (1996). The changing role of health care personnel in health and health care management. Social Science \& Medicine, 43(5), 799-808.

Kelly, S. (2008). Leadership: a categorical mistake? Human Relations, 61(6), 763-782.

Kitchener, M. (2000). The bureaucratization of professional roles: the case of clinical directors in UK hospitals. Organization, 7(1), 129-154.

Klein, R. (2006). The New Politics of the NHS. Oxford: Radcliffe.

Klein, R. (2008). The Bevan-Morrison debate: the shape of things to come in the NHS? CHPH Annual Lecture, London School of Hygiene and Tropical Medicine, 12 November.

Knights, D., \& Willmott, H. (1989). Power and subjectivity at work: from degradation to subjugation in social relations. Sociology, 23(4), 535-558.

Learmonth, M. (2005). Doing things with words: the case of management and administration. Public Administration, 83(3), 617-637.

Learmonth, M. (2009). 'Girls' working together without 'teams': how to avoid the colonization of management language. Human Relations, 62(12), 1887-1906.

Martin, G.P. (2008). 'Ordinary people only': knowledge, representativeness, and the publics of public participation in healthcare. Sociology of Health \& Illness, 30(1), 35-54.

Martin, G.P. (2009). Whose health, whose care, whose say? Some comments on public involvement in new NHS commissioning arrangements. Critical Public Health, 19(1), 123132.

Martin, G.P., Currie, G., \& Finn, R. (2009). Leadership, service reform, and public-service networks: the case of cancer-genetics pilots in the English NHS. Journal of Public Administration Research \& Theory, 19(4), 769-794.

Motion, J., \& Leitch, S. (2009). The transformational potential of public policy discourse. Organization Studies, 30(10), 1045-1061.

Newton, T. (1998). Theorizing subjectivity in organizations: the failure of Foucauldian studies? Organization Studies, 19(3), 415-447.

NHS Institute (2005). NHS Leadership Qualities Framework. http://www.nhsleadershipqualities.nhs.uk/, accessed 3 March 2010. 
This is an electronic version of an article published in Social Science \& Medicine. (C) 2012 Elsevier Limited

Parker, M. (2000). Organizational Culture and Identity. London: Sage.

Parker, M. (2004). Structure, culture and anarchy: ordering the NHS. In M. Learmonth \& N. Harding (Eds.), Unmasking Health Management (pp.171-185). New York: Nova Science.

Parker, M., \& Dent, M. (1996). Managers, doctors and culture: changing an English health district. Administration \& Society, 28(3), 335-361.

Robinson, S.K., \& Kerr, R. (2009). The symbolic violence of leadership: a critical hermeneutic study of leadership and succession in a British organization in the post-Soviet context. Human Relations, 62(6), 875-903.

Rose, N. (1990). Governing the Soul. London: Routledge.

Royle, N. (2000). What is deconstruction? In N.Royle (Ed.), Deconstructions (pp.1-13). Basingstoke: Palgrave.

Smircich, L. \& Morgan, G. (1982). Leadership: the management of meaning. Journal of Applied Behavioral Science, 18(3), 257-273.

Spillane, J.P. (2005). Distributed leadership. Educational Forum, 69(2), 143-150.

Stewart, R. (1989). Leading in the NHS. Basingstoke: Macmillan.

Walshe, K. (2003). Foundation hospitals: a new direction for NHS reform? Journal of the Royal Society of Medicine, 96(3), 106-110. 